\title{
Fiscal effects and the potential implications on economic growth of sea level rise impacts and coastal zone protection
}

\author{
Ramiro Parrado* a, b, Francesco Bosello ${ }^{a, c}$, Elisa Delpiazzo ${ }^{\mathrm{a}, \mathrm{b}}$, Jochen Hinkel ${ }^{\mathrm{d}}$, Daniel Lincke \\ ${ }^{\mathrm{d}}$, Sally Brown ${ }^{\mathrm{e}}$ \\ ${ }^{a}$ RFF-CMCC European Institute of Environmental Economics, Centro Euro-Mediterraneo sui \\ Cambiamenti Climatici, Venice, Italy \\ ${ }^{\text {b }}$ Ca' Foscari University, Venice, Italy \\ c University of Milan, Milan, Italy \\ d Global Climate Forum, Germany \\ e University of Southampton, United Kingdom
}

\begin{abstract}
Climate change impacts on coastal zones could be significant unless adaptation is undertaken. One particular macro-economic dimension of sea level rise (SLR) impacts that has received no attention so far is the potential stress of SLR impacts on public budgets. Adaptation will require increased public expenditure to protect assets at risk and could put additional stress on public budgets. We analyse the macroeconomic effects of SLR adaptation and impacts on public budgets. We include fiscal indicators in a climate change impact assessment focusing on SLR impacts and adaptation costs using a computable general equilibrium model extended with a detailed description of the public sector. Coastal protection expenditure is financed issuing government bonds, meaning that coastal adaptation places an additional burden on public budgets. SLR impacts are examined using several scenarios linked to three different Representative Concentration Pathways: 2.6, 4.5 and 8.5, and two Shared Socio-economic Pathways: SSP2 and SSP5. Future projections of direct damages of mean and extreme SLR and adaptation costs are generated by the Dynamic Interactive Vulnerability Assessment framework. Without adaptation, all world regions suffer a loss and public deficits increase respect to the reference scenario. Higher deficits imply higher government borrowing from household savings reducing available resources for private investments therefore decreasing capital accumulation and growth. Adaptation benefits result from two mechanisms: i) the avoided direct impacts, and ii) a reduced public deficit effect. This allows for an increased capital accumulation, suggesting that support to adaptation in deficit spending might trigger positive effects on public finance sustainability.
\end{abstract}

Keywords: Adaptation, sea level rise, public budgets, sustainability, climate change, computable general equilibrium

* Correspoding author: Ramiro Parrado

Centro Euro-Mediterraneo sui Cambiamenti Climatici

Edificio Porta dell'Innovazione - Piano 2

Via della Libertà, 12 - 30175, Venezia Marghera (VE), Italy

Tel: +39041.234 6059

E-mail: ramiro.parrado@cmcc.it

\section{Acknowledgements}


The authors gratefully acknowledge funding from the European Union under contract number EVK2-2000-22024 to develop the Dynamic Interactive Vulnerability Assessment (DIVA) model. The data was extracted from the model from the Inter-Sectoral Impact Model Intercomparison Project Fast Track funded by the German Federal Ministry of Education and Research (Project 01LS1201A). Further analysis occurred under the European Commission's Seventh Framework Programme's collaborative project RISES-AM-(contract FP7-ENV-2013-two stage-603396).

We also acknowledge funding from the European Union's Seventh Framework Programme for research, technological development and demonstration for the ECONADAPT project under grant agreement no 603906; and from the Italian Ministry of Education, University and Research and the Italian Ministry of Environment, Land and Sea under the GEMINA project. 


\section{Fiscal effects and the potential implications on economic growth of sea-level rise impacts and coastal zone protection}

\section{Introduction}

Sea-level rise (SLR) threatens coastal zones, through salinization, flooding, erosion, land loss (Hoegh-Guldberg et al. 2018; Wong et al. 2014; Nicholls et al. 2007; Nicholls et al 1999), and damage to property and infrastructure, which along with associated disruptions could result in adverse economic effects unless adaptation is undertaken. As coastal zones contain large population densities and economic activities (World Bank, 2010; Neumann et al. 2015; McGranahan et al. 2007) compared with further inland, it is important to project the wider economic effects of adverse change. With rates of SLR projected to accelerate (Church et al. 2013) and increasing populations and socioeconomic development, a larger number of people and assets will be at risk from coastal inundation unless further action is undertaken (Wong et al., 2014). For example, according to Hinkel et al. (2014) with $0.25 \mathrm{~m}-1.23 \mathrm{~m}$ of SLR in 2100 and no further adaptation, millions of people may be flooded, and annual losses may be $0.3 \%$ 9.3\% of GDP. Globally, the broad impacts and direct costs of SLR and adaptation have been well identified (e.g. Hinkel et al. 2015), but the wider macro-economic implications have not been fully analysed yet.

One particular macro-economic dimension of SLR impacts that has received no attention so far is the potential stress on public budgets. This issue was initially introduced, in broader terms, by Heller (2003) indicating climate change as one of the major threats posed on public budgets in future decades along with demographic changes. On the one hand, fiscal revenues could be significantly reduced in countries depending on few climate sensitive economic sectors. On the other hand, public spending may increase to prevent impacts such as intensified incidence of vector borne diseases, population movements or stress on infrastructures. Against this background, public budgets could become affected by climate change as decreasing revenues along with rising expenditures would erode public sector's ability to pay, especially if long-term economic growth potential becomes compromised (Farid et al., 2016).

Most of the discussion and research on fiscal effects has however focused on mitigation because of the direct effects on public budgets through variations in tax revenues due to policy implementation. There is a vast literature, developed especially during the 1990s, dealing with fiscal implications of carbon-energy taxes, revenue rising potential, re-distributional implications, as well as costs and fiscal efficiency of green fiscal reforms (see e.g. Park and Pezzey, 1998; Bosello et al., 2001; and Schoeb, 2005 for surveys). Much thinner is the literature concerning fiscal implications of climate change impacts and adaptation. Ekins and Speck (2013) discuss extensively the fiscal sustainability concept in relation with climate change impacts and policies highlighting the need to investigate their connections. Jones et al. (2013) review the corresponding fiscal challenges posed by climate change mitigation and adaptation describing climate change as a fiscal issue and stressing the fact that climate change impacts will indirectly affect government revenues and expenditures. Within the disaster risk management literature Hochrainer-Stigler et al. (2014) focus on the fiscal implications of climate-related impacts by employing risk-based modelling techniques and considering estimates related to current climate which could be used as a baseline for discussion of projected risks.

For completeness, it is worth mentioning the studies providing quantifications of adaptation costs and finance needs for adaptation (see e.g. Buchner et al. 2015, UNEP 2016). 
Nonetheless, macro-economic assessments investigating this issue are scarce. Still, using a systemic approach able to address all direct and indirect effects on the economy can be useful as emphasized by Ekins and Speck (2013). Consolidated tools for assessing economy-wide effects are Computable General Equilibrium (CGE) models which include feedbacks and interdependencies between different markets. Indeed, CGE analyses have been widely applied to the economic assessment of climate change impact, but fiscal consequences have been somewhat left aside. To the best of our knowledge, only Bachner and Bednar-Friedl (2018) addressed with a CGE model how public budgets are affected by climate change. Investigating ten different impact areas in Austria, they find that macro-economic feedback effects on the overall tax base double the initial direct effect on the expenditure side of public budgets.

Applying this approach to study fiscal implications of coastal protection is relevant as, on the one hand, the vast majority of investments against SLR in Europe are indeed publicly financed (CEPS and ZEW 2010, Nicholls et al.2010). On the other hand, insufficient protection would anyway increase public expenditure through disaster relief payments and compensation schemes. Both channels will affect public budgets. Eventually, adaptation could reduce or increase the stress on public budgets depending on its effectiveness, the structure of the tax system, the size of adaptation investment, and the funding sources available (Osberghaus and Reif 2010).

It is also important to highlight the difference between mitigation and planned adaptation. The impact of the former on public budgets is much more direct, especially when implemented through carbon energy taxes or subsidies. The latter operates mostly through regulation or through public expenditure programs that are not financed by dedicated taxes, but by the general taxation. Thus, the budgetary implications are more difficult to track.

A wide range of studies assess economic impacts of climate change-induced SLR using CGE models either analysing SLR as a single impact (Darwin and Tol 2001; Bosello et al. 2007; Bosello et al. 2012a; Pycroft et al. 2015 and Tol et al. 2016, Joshi et al., 2016), or including SLR as part of a wider set of impacts (Deke et al. 2001; Bigano et al. 2008; Eboli et al. 2010; Ciscar et al. 2009, 2011, 2012, 2014, 2018; Aaheim et al. 2012; Roson and van der Mensbrugge 2012; Bosello et al. 2012b; Dellink et al. 2014; OECD 2015).

The main contribution of this paper is to address, differently from the abovementioned studies, the missing inclusion of fiscal indicators in climate change impact and adaptation assessments.

Additional differences of this paper compared to previous studies are: i) the inclusion of potential damages of extreme sea-level events, i.e. those related to 1-10,000 year flood, into the calculation of expected annual direct damages in DIVA and ii) including those expected annual direct damages as capital stock losses in a recursive dynamic setting in order to assess indirect economic effects. While the focus of previous CGE studies is the gradual loss of capital stock related to land submerged by mean sea-level examined in comparative static exercises, we setup a dynamic recursive exercise to analyse potential growth effects. This does not imply modelling explicitly extreme events in the CGE framework but, as mentioned before, it means that the exercise uses information of expected annual direct damages which take into account extreme events. It is worth noting that extreme sea-level events, although less frequent, could potentially induce a much higher damage on coastal assets, dynamic effects on growth and higher demand for protection. We acknowledge that single extreme events can cause damages much higher than the expected damages, and that properly assessing extreme events would require a different approach. However, the expected damages give an indication where high damages could potentially occur and also allow for an assessment over longer time periods where single extreme events are included as part of long-term average damages. 
In this paper SLR is investigated with a recursive-dynamic CGE model extended with a detailed description of the public sector (Delpiazzo et al. 2017) that enables the analysis of macroeconomic effects of adaptation and impacts on public budgets. More specifically, we evaluate the economic implication of SLR-induced land and capital losses as well as labour productivity effects due to temporary labour force displacements without and with coastal protection financed issuing government bonds. The choice to support adaptation through public borrowing and not taxation is made on purpose, to study consequences in a potentially more stressful conditions for public funds.

We examine several SLR scenarios originated by linking three different Representative Concentration Pathways (RCP): RCP 2.6, 4.5 and 8.5 (produced by two climate models), and two Shared Socio-economic Pathways (SSP): SSP2 and SSP5 while accounting for uncertainty in land-based ice melt. This combination allows us to span low, medium and high climate change futures and to account for different types of socio-economic development, and accordingly, different exposure to SLR: a medium one (SSP2) and a high one related to higher GDP and different population at risk (SSP5). For these scenarios, future projections of direct damages of mean and extreme SLR and adaptation costs are generated by the Dynamic Interactive Vulnerability Assessment (DIVA) modelling framework (Hinkel et al 2013, 2014; Vafeidis et al. 2008), an integrated socio-economical and geo-bio-physical model.

As a final disclaimer: it is important to stress that we do not aim to perform an analysis of SLR risk. CGE models have many shortcomings under this respect. Rather, we apply CGE modelling to get insights of higher order effects on long-term debt sustainability of climate change impacts and adaptation expenditure in the specific context of coastal protection.

\section{Methodology}

Following a conceptual model from Sue Wing and Fisher-Vanden (2013), adaptation measures can be classified in three types. Type I is related to market-driven (autonomous) adaptation triggered by price signals. Type II refers to specific protective/defensive measures to reduce physical impacts. Type III consists of further compensating measures (e.g. fiscal policies) that reduce the adverse effects on economic sector's productivity. Type I is standard in CGE models that feature endogenous price adjustments, but also the last two types, building the so-called planned adaptation, have ample potential to be implemented in CGE models (Sue Wing and Fisher-Vanden 2013).

In the case of SLR, coastal protection expenditures mainly consist of large infrastructure expenditures which are primarily financed by public funds. According to CEPS and ZEW (2010) more than $95 \%$ of investments against SLR in Europe are publicly funded. Nicholls et al. (2010) suggest that much of the costs for adaptation to SLR falls on government finance while only a minority of adaptation (i.e. port and harbour upgrade) could be funded by private investments.

Against this background, this work implements in a recursive-dynamic CGE model, public planned expenditures targeted to coastal protection inclusive of investment and maintenance costs corresponding to Type II adaptation measures. Cost estimation of coastal defences, consisting in sea dikes to protect against flooding, stems from the DIVA model. These are empirically derived based on a 'demand for safety' function based on per-capita income and population density (Hinkel et al. 2014 see Section 2.3). The DIVA model does not account for autonomous (Type I) adaptation, this is captured by the CGE model where resources allocate across sectors and countries responding to changes in relative prices. 


\subsection{Overview of the ICES-XPS model}

The economic assessment is based on an extended version of the ICES CGE model used in climate change impact and policy assessments (Bosello and Parrado 2014; Bosello et al. 2012b; Eboli et al 2010). The basic version is a recursive-dynamic multi-sector multi-country CGE model derived from the GTAP model (Hertel et al. 1997). Like many global CGE models, ICES proposes a simplified representation of government behaviour.

The original demand side in the model is represented by a utility maximizing regional household that allocates its income among private expenditure, public (government) expenditure, and savings. A budget constraint exists for the regional household as a whole but not for the government. Accordingly, government expenditures could, for instance, move in the opposite direction to taxes. Public debt and deficit are ignored, therefore the possibility for the public sector to save is not considered at all. This representation offers many advantages allowing for a single utility characterizing the demand side and avoiding complex public sector data issues on availability and homogeneity (for a more technical discussion refer to Delpiazzo et al. 2017 and Hertel 1997). However, it is inadequate when effects on public spending, like that of adaptation, have to be evaluated. To address this issue, we use the ICES-XPS (ICES-eXtended Public Sector) ${ }^{1}$ model which features the government as a separate actor with its own budget constraint. Government transfers, consumption, and investments build government expenditure, while government income derives from taxes. At the regional level investments can be both private and public and are homogeneous. Furthermore, the model now includes items such as transfers between governments and households, and interest payments on debt stock. There are also transfers among governments.

This section presents a short description of the public sector's budget. A detailed description of the public sector is in Appendix A of the Supplementary Material (SM). In ICES-XPS, the government is a separate agent, whose income is affected by: (i) tax revenues (TTAX $)$; (ii) net transfers to private households $\left(N T P H_{r}\right)$; (iii) net interest payments to resident and non- resident households $\left(Y G I_{r}\right)$; and (iv) net foreign transfers among governments $\left(N F T_{r}\right)$. Government income is used for consumption $\left(G O V_{-} E X P_{r}\right)$ and savings $\left(S A V_{-} G O V_{r}\right)$. The following two equations represent the government income respect to sources and uses.

$$
\begin{gathered}
Y G_{r}=T T A X_{r}+N T P H_{r}-Y G I_{r}+N F T_{r} \\
Y G_{r}=G O V_{-} E X P_{r}+S A V_{-} G O V_{r}
\end{gathered}
$$

Total regional investments are modelled through a Cobb-Douglas function of private and public investments. Regional investment net of depreciation $\left(N E T I N V_{r}\right)$ is split into public $\left(G O V_{-} I N V_{r}\right)$ and private investments (PRIV_INV $\left.V_{r}\right)$ according to fixed shares.

$$
N E T I N V_{r}=G O V_{-} I N V_{r}+P R I V_{-} I N V_{r}
$$

The gap between public savings and public investments represent the government's financial needs (borrowing). This gap is financed by households' savings, since both domestic and foreign households supply a homogenous saving commodity.

$$
G B O R_{r}=G O V_{-} I N V_{r}-S A V_{-} G O V_{r}
$$

\footnotetext{
${ }^{1}$ The detailed description of the public sector in the ICES-XPS and the regional aggregation is in Appendix A of the Supplementary Material (SM).
} 
A positive value of $G B O R_{r}$ means a deficit, thus the government is borrowing, while a negative sign means a surplus so that the government is lending resources. Then, public debt at the end of year $t\left(G D E B T_{t, r}\right)$ accumulates by adding current government's borrowing $\left(G B O R_{t, r}\right)$ to the existing debt stock $\left(G D E B T_{t-1, r}\right)$.

$$
G D E B T_{t, r}=G D E B T_{t-1, r}+G B O R_{t, r}
$$

Interest payments on government's debt stock $\left(Y G I_{r}\right)$ are determined by a constant exogenous interest rate $\left(i r_{r}=4 \%\right)$ multiplied by the related previous year debt stock. ${ }^{2}$

$$
Y G I_{t, r}=i r_{r} \cdot G D E B T_{t-1, r}
$$

Since public and private savings are homogenous goods, private households lend a fraction of their savings to governments and, as a consequence, governments pay interests to households. Thus, government borrowing reduces the available savings for productive investment purposes which in its turn will increase private sector interest rates given that investments demand will face a lower savings supply. Note that these interest rates are different from the constant interest rate set for public debt.

The remaining features of ICES-XPS are similar to ICES. Output is produced by a representative firm in each sector using primary factors (land, labour, natural resources, capital), and other goods and services. Capital and labour are perfectly mobile domestically but immobile internationally. All data is available at the regional level and there is no distinction between urban and rural dimensions. Investment is allocated across countries to equalize expected rates of return to capital in the long-run. Savings and investments are equalized at the world level, but each region could have an imbalance between disposable savings and investment demand. This imbalance is closed by a surplus/deficit in foreign transactions (considered as the sum of trade surpluses/deficits and the net inflows of international transfers). In this context, government borrowing reduces the availability of regional savings with a consequent increase in saving prices which are negatively correlated to the rate of return to capital.

\subsection{Implementing adaptation in ICES-XPS model}

In our set up, 'Planned Adaptation' in coastal protection means investing in protective infrastructure, such as dikes to safeguard coastal zones where there are high population densities. Once these measures have been put in place (and assuming that maintenance occurs to ensure their effectiveness) only a residual damage will remain. However, adaptation is costly. Costs are of two types: i) investments in protective infrastructure, and ii) maintenance costs. We draw this information from DIVA (see next section).

\footnotetext{
${ }^{2}$ The assumption that public debt is always refinanced at a constant rate is in fact a coarse simplification of the real world, ruling out the possibility to link interest rates to perceived changes in the debt-risk profile of a region (more on this on the discussion section). A straightforward alternative would have been to set the interest rate for public debt at the regional rates of return to capital endogenously computed by the CGE model. However, these are in fact decreasing in all our scenarios, as the embedded growth assumptions imply higher capital supply. As a consequence, the burden of the public debt would actually decrease leading perhaps to too optimistic conclusions about debt sustainability. The further option to model a more sophisticated public debt system with international capital markets and a financial module is left to further research.
} 
It is assumed that both expenditures are financed by private savings, through households buying government bonds. Thus, adaptation expenditures reduce the availability of savings for investment purposes. Furthermore, while expenditure in dike construction is accounted as public investment, maintenance costs expand government recurrent expenditure.

Public investments with additional adaptation to cope with SLR (GOVINV_AD) in region $r$ become:

$$
\text { GOVINV_AD } D_{r}=G O V I N V_{r}+\triangle G O V I N V_{C N S T, r}
$$

Where GOVINV $V_{r}$ represents the initial public investments of region $\mathrm{r}$, and $\triangle G_{\text {GOVINV }}$ CNST, represents the additional public investment in infrastructure for the construction of dikes.

Total recurrent government expenditures in region $\mathrm{r}\left(T Q G_{r}\right)$ is the sum of each recurrent expenditure $\left(Q G_{i, r}\right)$ in good or service $i$ :

$$
T Q G_{r}=\sum_{i}^{n} Q G_{i, r}
$$

Maintenance costs are additional recurrent public expenditures addressed to the construction sector that provides maintenance services $(i=C N S T)$. Similar to public investments with adaptation, the government demand for construction services with additional adaptation $\left(Q G_{-} A D_{C N S T, r}\right)$ becomes:

$$
Q G_{-} A D_{C N S T, r}=Q G_{C N S T, r}+\Delta Q G_{C N S T, r}
$$

which ends up increasing total recurrent government expenditure by the same amount $\left(\triangle Q G_{C N S T, r}\right)$ to obtain total recurrent government expenditure with additional adaptation $\left(T Q G_{-} A D_{r}\right)$

$$
T Q G_{-} A D_{r}=\sum_{i}^{n} Q G_{i, r}+\Delta Q G_{C N S T, r}
$$

This way of modelling adaptation expenditures implies that total public expenditure expands, and so does the public deficit, which is financed with private savings. This ends up reducing total savings each year. Due to public borrowing, interest payments increase which also augments the public deficit in the future. Hence, by conveying part of household savings to the funding of adaptation expenditures, planned adaptation decreases the total resources available to invest and build capital stock. ${ }^{3}$

Therefore, this assessment can verify whether or not the lower growth of capital stock induced by adaptation is more than compensated by the lower climate-change induced losses on capital, land stock, and labour productivity; and how all this affects public budgets.

3 This way to model adaptation rules out the possibility for adaptation (and more generally public) expenditure to be expansive through multiplier effects. The model however is a general equilibrium one, with growth originated by savings and not by Keynesian demand-driven effects. Adding that feature to public adaptation would imply extending it also to all form of consumption changing the nature of model. 


\subsection{Sea-level rise impacts and adaptation costs}

The direct damage costs of SLR and of coastal protection (building of sea dikes) are derived from the DIVA framework (Hinkel et al. 2014; Hinkel et al. 2013; Hinkel et al. 2012; Hinkel and Klein 2009). SLR leads to a range of coastal impacts including loss of land due to submergence by gradual SLR, damage to coastal assets due to higher extreme sea-level events, impeded drainage, salinity intrusion, enhanced coastal erosion and wetland change (Wong et al. 2014). Here we cover only the first two types of impacts as global impact estimates of the other types of impacts are difficult to obtain.

Residual impacts depend on adaptation measures that in DIVA take the form of dike building. DIVA computes protection standards, directly connected to the height of dikes, for over 12,000 sections of the world's coast based on an empirically derived demand for safety function that is increasing with per-capita income and population density (Hinkel et al. 2014). The dike building process is stylized as data to derive current and future protection levels worldwide with higher granularity are not available. The demand for safety and thus of higher dikes depends positively on the SLR stressors (extreme water level), GDP per capita and population density. Accordingly, in DIVA coastal protection and the related costs - that include construction and annual maintenance costs - change because of environmental and socio-economic drivers (for further detail see Hinkel et al 2014). Results used in this paper differ from previous assessments (e.g. Ciscar et al 2012) due to new science and accompanying data. This includes new data sets on extreme water levels (Muis et al. 2017), topographic data (Jarvis et al., 2008; USGS, 2015), land level data relating to glacial isostatic adjustment (Peltier 2004), population exposed to flooding (Balk et al., 2006; CIESIN et al., 2011) and re-writing of algorithms with the latest science, such as a statistically derived asset to gross domestic product ratio based on Hallegatte et al. (2013) with the digital elevation data and depth-damage curves (Hinkel et al. 2014).

Direct impacts and adaptation costs are computed for a "No additional adaptation scenario", assuming constant protection at 1995 levels and for a "With adaptation scenario", where the demand for safety increases with increasing affluence and higher dikes are built with rising sealevels. The costs of coastal protection include construction and annual maintenance costs. Information is available in 5-year time steps.

The No additional adaptation scenario could be considered not very realistic given that protection levels will not actually be frozen at 1995 levels. Nonetheless, this is a necessary reference point to enable a full account of the potential future contribution of adaptation expenditure on public budgets.

For each combination of SLR and socio-economic scenario (with no additional adaptation and with adaptation), the following DIVA model output were used as input to ICES-XPS:

a) Annual land loss due to submergence ( $\mathrm{km}^{2} /$ year): Land is considered to be unusable, and thus lost, if it is situated below the 1-in-1 year flood water level and not protected by a dike.

b) Expected annual damages to assets by sea floods (million US\$/year): mathematical expectation of damages to assets integrating from the 1-in-1 year flood to the 1-in10,000 year flood.

c) Expected annual number of people flooded per year (thousands/year): mathematical expectation of damages to people integrating from the 1 -in-1 year flood to the 1 -in10,000 year flood.

d) Annual cost of construction of new dikes as well as raising of existing dikes (million US\$(year). 
e) Annual cost of maintaining existing dikes, projected at $1 \%$ of capital costs (million US\$/year). Dikes that are overtopped by rising sea-level are no longer maintained.

For a consistent flow of information across the two models, all values from DIVA, expressed in US\$ PPP (Purchasing Power Parity) were converted to US\$ MER (Market Exchange Rate), the ICES-XPS reference, using the conversion factors from the World Development Indicators (World Bank 2017). The physical and economic data of the spatially resolved DIVA model were aggregated to match the ICES-XPS regions. Then we calculated the ratio of each monetary value to the corresponding GDP for each SSP. Finally, those ratios were applied to the ICESXPS GDP database to compute the corresponding monetary values to be included as input for the CGE simulations.

As in previous CGE assessments (Bosello et al. 2007, 2012a, 2012b), we assume that SLR impacts affect regional performances through land loss, labour productivity loss, and capital loss. The first is implemented in ICES-XPS decreasing the stock of productive land available to agriculture assuming this coincides with submerged land, which is commonly observed. Labour productivity is reduced assuming that people flooded are not able to work for 2 working weeks per year. ${ }^{4}$ Capital stock is decreased according to the expected annual damages to assets by sea floods. This presupposes that all countries of the world would experience in every year a flood that provokes exactly the expected damage. We acknowledge this is unrealistic, but we keep this assumption for simplicity noting that our results, under this respect, can be placed in the high-range of damage estimates. ${ }^{5}$

It is also worth noting that this is the first time that we are able to include explicit estimates of capital losses. Previous assessments run with prior versions of the same CGE model did not include them at all (Bigano et al, 2008; Bosello et al. 2012a; Eboli et al. 2010), or followed a rather coarse method imposing the same loss of land stock on capital stock (Bosello et al. 2007, Bosello et al. 2012b, Bosello and Parrado 2014). This is an improvement to our impact analysis, and therefore, we should expect higher economy-wide impacts in this study.

\subsection{Scenarios}

The main drivers of the DIVA model are SLR and the evolution of population density and gross domestic product (GDP). Projections for both variables associated to two Shared Socioeconomic Pathways - SSP (O'Neill et al. 2014): SSP2 "Middle of the Road" and SSP5 "Fossil-fuelled development", both available at IIASA (2016) have been used in this study. The evolution of GDP, population, and capital stock for both scenarios is shown on Figure SM 1 of the Supplementary Material (SM).

SLR scenarios generated from two climate models: Nor-ESM (Bentsen et al. 2013) and MIROCESM (Watanabe et al. 2011) and for three Representative Concentration Pathways (van Vuuren et al. 2011) were analysed: RCPs $2.6,4.5$, and 8.5. Furthermore, to account for uncertainty in land-based ice melt, the $5 \%, 50 \%$, and $95 \%$ percentiles ice melting uncertainty were considered

\footnotetext{
4 This value is rather arbitrary and derives from assumptions made in Bosello et al (2012b) on the period of time that people will not be able to work after being affected by river floods. To control for the weight of this assumption we run a sensitivity analysis considering 1, 2, 4 and 6 weeks for the No Adaptation scenario with high SLR. Applying these periods does not change the final outcome of our estimates. There is some variability on impacts at the aggregate level for North Europe and Asian countries, but these variations do not change the overall results of our study. As a final remark, it has to be noted that the labour productivity effect represents anyway a minor share (1\% to $16 \%)$ of the total impact.

${ }^{5} \mathrm{We}$ acknowledge that the probability of this happening in reality is null. Addressing this would, however, require a quite different approach such as a Monte-Carlo analysis which we plan to address in the future.
} 
as representing a 'very likely' range for low, medium, and high SLR estimates in each scenario (see Figure SM 2). These regionalised (patterned) SLR scenarios are taken from Hinkel et al. $(2014){ }^{6}$

The general equilibrium analysis is developed comparing the adaptation scenarios against a reference scenario.

Reference (no impact): Considering only the socio-economic scenarios based on the SSP2 and SSP5. These scenarios do not include any impact from SLR.

No additional adaptation: Including SLR impacts, as reported in section 2.3 and considering both socio-economic development and SLR. This represents a counter factual scenario with adaptation frozen at 1995 protection levels.

With additional adaptation: Including public intervention to protect coastal zones against SLR as prescribed by the DIVA framework, considering both socio-economic development and SLR, including residual damages, imposed according to the description in section 2.3. In ICES-XPS we take into account only the additional costs for maintenance of the new infrastructure. Maintenance costs related to existing protection infrastructures are not a consequence of climate change impacts (Hinkel et al., 2014) and are thus assumed to be part of the reference scenario.

\section{Results}

Direct impacts of SLR and coastal protection provided by DIVA are summarised in Appendix D of the SM. Benefits are higher than costs, as amply recognised by an extended literature. This information constitutes the main input for the following CGE analysis meant to capture the economy-wide feedbacks and fiscal effects of protecting coastal zones, i.e. the role of autonomous adaptation.

Macro-economic effects are summarised in Figure 1 comparing impacts on regional GDP by SSP for RCPs 2.6, 4.5, and 8.5 in 2050 with and without additional adaptation (full results are reported in Figure SM 5). The figure includes a boxplot with whiskers computed using 1.5 times the interquartile range showing outliers outside that interval. The No additional adaptation scenarios feature a generalized GDP loss in all regions for all RCPs directly dependent on the size of impacts on capital, land, and labour productivity. The most affected region is China, which shows also a higher variability in impacts, with an average GDP loss of $10 \%$ for SSP5 and $8.6 \%$ for SSP2. South Asia is the second most affected region in SSP5 with an average GDP loss of $7.2 \%$ but a much lower one for SSP2 (3.3\%). East Asia shows also high losses (SSP5: 5.6\%, SSP2: 4.6\%); along with North Europe (SSP5: 5.3\%, SSP2: 4.4\%). In the rest of Asian countries, Middle East, Africa, Canada, Europe, Oceania, USA, Latin America and the Caribbean, GDP could decrease on average around $4 \%$ to $2 \%$. The rest of the Former Soviet Union and Sub Saharan Africa show lower impacts with narrower loss intervals and an average below than $2 \%$ of GDP.

\section{Fig. 1 Impacts on real GDP by region, SSP, and RCP in 2050 (with and without additional adaptation)}

\footnotetext{
${ }^{6}$ The regional patterns are from the Greenland and Antarctic ice sheets and their peripheral glaciers and ice caps, plus from the steric contribution of SLR. A global mean value is added to the regionalised components from glaciers and ice caps in other parts of the world.
} 
By comparing results between SSP5 and SSP2, it emerges that higher growth implies higher exposure and impacts. As in the case of direct impacts, the variability in macro-economic results induced by differences in socioeconomic development is higher than that associated to the climate scenarios. This is a consequence of the time profile of our exercise, as by mid-century, climate signals are quite similar across RCPs. The macro-economic benefits of coastal protection are substantial. Figure 1 clearly highlights the ability of adaptation to reduce GDP losses, particularly evident in those regions like Asian countries, where SLR has more pronounced impacts.

This positive result of adaptation is the compounded effect of two mechanisms directly and indirectly related with SLR impacts. The first one regards the avoided direct impacts (loss of labour productivity, land, and capital). In this case, the avoided capital loss is the main driver of adaptation benefits, not only because of their size, but also due to their key role in determining growth in a recursive dynamic model like ICES-XPS.

\section{Fig. 2 Impacts on public deficit by region, SSPs and RCPs in 2050 (with and without additional adaptation)}

The second mechanism is the public deficit effect (Figure 2 and Figure 3) that has an indirect consequence on GDP growth. In 2050, without adaptation, all regions increase their public deficits or reduce their surpluses respect to the reference scenario. Region-specific results are strictly dependent on the tax system structure, and on the interaction between input taxes (affected by the negative effects on land, capital, and labour), and output taxes (affected by the decline in GDP). Public deficit expansion in non-Asian countries is mainly driven by the reduction in GDP and consequently lower tax revenues. In contrast, countries from Asia and the Middle East enlarge their deficit mainly due to an increase of public expenditures. This is due to the fact that these regions, being highly damaged by SLR experience a noticeable rise in prices due to a loss of endowments, in particular capital stock. This directly affects government expenditures. These increases can be substantive in absolute terms. In RCP8.5 and high SLR for instance, they amount in 2050 to more than $\$ 800$ billion in China, \$236 billion in Latin America and the Caribbean, $\$ 180$ billion in India, and $\$ 171$ billion in East Asia. Full results including decomposition of fiscal effects during the period 2008-2050 are reported in Figure SM 6, Figure SM 7, Figure SM 8, and Figure SM 9.

A higher deficit implies higher government borrowing from household savings which eventually reduces also the available resources for private investments, decreasing capital accumulation and growth in the medium- and long-run.

Adaptation translates the lower impacts of SLR into lower deficits with the government borrowing less from households which would allow for an increased capital accumulation in the long-run. Lower deficits imply also lower debt accumulation and a lower debt service. This allows more resources devoted to growth. Note that this result holds even though adaptation is funded issuing public debt. Figure 3 highlights the patterns in the evolution of deficit (with and without additional adaptation) in selected regions for the period 2007-2035. Initially, public deficits are in fact higher when adaptation investments are being put in place, but in the longer run they become lower as increasingly negative impacts are avoided. In the long-term GDP losses and public deficits would be much higher without adaptation (see Figure SM 5 and Figure 
SM 6). Eventually, according to the ICES-XPS analysis, the protection investments prescribed by DIVA are also robust in a general equilibrium setup, i.e. accounting for the full economic interactions.

\section{Fig. 3 Impacts on public deficit by SSP and RCP for selected regions (with and without additional adaptation)}

Within this context and for the case of SLR, support to adaptation in deficit spending could improve GDP growth in the long-run and might trigger positive effects on public finance sustainability (see Figure SM 9 for the positive effect of adaptation in reducing the public deficit compared against the No additional adaptation case).

\section{Discussion}

This study's macro-economic impacts of SLR are much higher than those reported by previous studies. For instance, the maximum loss from Bosello et al. (2007), Bigano et al, (2008), Eboli et al. (2010), Bosello et al. (2012a,b), and Bosello and Parrado (2014) is 0.4\% of GDP in 2050. OECD (2015), which applies a similar methodology to simulate capital stock losses - i.e. capital decreases in pace with land loss - estimated a maximum GDP contraction of less than $1 \%$ in the Asian region in 2050. The PESETA III study (Ciscar et al. 2018) computes roughly a $0.3 \%$ GDP loss for the EU and around $0.5 \%$ for UK and Ireland. Our higher loss estimates are mainly due to three aspects. The first and most important is the use of extreme SLR estimates related to a 1-10,000 year flood which implies higher impact and adaptation costs. Related to this is the fact that capital losses have been estimated with the DIVA model and not inferred from land losses. The second, is the recursive dynamic setting that amplifies effects on growth compared to static exercises (as for instance Ciscar et al. 2009, 2011, 2012, 2014, 2018). The third, pertains finally to the inclusion of public borrowing effect that crowds savings out and therefore investments with a further negative impact on growth. This is more evident in the no additional adaptation-high SLR scenarios where governments face larger deficits. Note that results are driven by the cost estimates of the DIVA model (that generally features lower adaptation costs than GDP losses), which are then used in the CGE model to calculate the second order impacts and the fiscal impacts from undertaking adaptation investments or not.

In the No Adaptation scenarios governments must borrow more resources than in the Adaptation scenarios. In the former scenarios governments increase their deficits (and public debts) due to lower tax revenues or increased current expenditures, then they must borrow from private households to finance the deficit which ends up increasing public debt as well as the debt burden. On the contrary, in the Additional Adaptation scenarios, even though the government is borrowing to finance adaptation investments and maintenance costs, the benefits are higher than the burden of the adaptation debt, since with adaptation governments have either higher tax revenues or lower current expenditures.

Debt sustainability could be compromised if interest payments become a heavy burden in public debts either because governments are borrowing more to refinance the existing debt or because interest rates are increasing due to a higher public debt. The evolution of public deficits is an indicator that reveals if public debt is becoming unsustainable because it is increasing in time. 
Figure SM 9 shows the temporal profile for changes of public deficits thanks to SLR adaptation (black line) along with the deficit decomposition by its main components for one specific scenario (SSP2, RCP8.5 and high SLR simulation scenario produced with the MIROC-ESM climate model). Debt is more sustainable in the Additional Adaptation scenarios due to higher tax revenues (blue area) in most of Non-Asian countries, while Asian countries improve their deficits with Adaptation thanks to lower expenditures (Orange area), and lower public debt interest payments (light orange area). Only North Europe shows a slight increase in public deficit after 2030 and this is explained by the high investments in dike building that must be done by 2030 and the corresponding increase in dike maintenance costs afterwards as shown in the second panel of Figure SM 10. For the rest of countries, adaptation expenditures (shown in Figure SM 10), do not represent an additional burden for debt sustainability even though they are financed with public debts through adaptation funds since the public deficit (black line in Figure SM 9) is always lower than in the No Adaptation scenario.

It is worth noting that some regions such as USA and North Europe may undertake higher adaptation expenditures than more vulnerable regions such as China and India (Figure SM 10). This is because adaptation responds to a demand-for-safety function driven by socio-economic indicators (GDP per capita and population density), that suggest higher protection levels (and thus higher costs) in richer areas like the USA and Northern Europe than in China and India.

There are two features of the study that can underestimate, the first, and overestimate, the second, our results on growth and public finance. As to the first: it is well known that financing government expenditure through new debt can be particularly troublesome, especially for highly indebted countries, if this action is linked to a perception of increasing risk of payback. Markets will typically react asking for higher rewards and interest rates. This dynamic however is not present in our exercise which may lead to underestimate the cost of raising public fund. As said, the reference scenarios examined are all quite optimistic in terms of growth rates which implies in fact a decrease in interest rates (there is more capital supply). This decrease, albeit less pronounced, is present also in SLR scenarios. Thus, to avoid an excessive underestimation of the cost of a debt policy, we set a fixed public debt interest rate. A more realistic representation of the dynamics of interest rates would have required a substantive revision of the capital market that we leave for further work. Despite this, the private sector of each regional economy in the model still responds to endogenous interest rates that are higher when the more government borrows from households.

This said, debt patterns in the adaptation scenarios, also in the initial simulation years when adaptation costs should prevail on benefits, do not change much compared with the baseline scenario. This would lead us to conclude that the debt-risk profile of the regions considered, will not be impacted too much by adaptation expenditure. Therefore, at the macro regional level considered at least, debt financing would not be rationed. However, this may not be the case for some individual countries.

The second feature refers to the inability to account for the expansive nature of adaptation expenditure on capital stock, whose positive effect is instead confined to damage reduction. This model feature can lead to underestimate the benefit of adaptation. There are indeed possible corrections for this, but this would imply to modify not just government consumption, but all the demand side of the model introducing multiplicative demand effects, a route that we did not follow. We acknowledge that this is a limitation of the approach. At the same time, correcting for it would have very likely strengthened our results.

A third point regards the disaster relief payments that have been disregarded in our analysis. While these payments can constitute an important part of public budgets, including them in our CGE framework would have only increased the gap between the No Adaptation and Additional Adaptation scenarios. As a matter of fact, this kind of payments would have been financed by 
borrowing more resources from the private sector with the corresponding impact on economic growth, even though part of those resources would have returned to the economy in the form of reconstruction investments and expenditures. However, the final outcome of the analysis would have been similar.

There is finally another important limitation inherent to a CGE assessment applied to the evaluation of extreme risk. ${ }^{7}$ Eventually, we assessed the indirect effects of expected annual losses. We tried to capture uncertainty through multi-scenario assessment, but the exercise remains basically a deterministic sensitivity analysis.

On the one hand, this applies to uncertainty related to the development of future socioeconomic scenarios. CGE models are meant to perform short to medium term analyses and are less reliable when the future can unfold quite differently from what implied by the calibrated parameterization. The standard way to deal with this issue is the one we followed here simulating different SSPS and providing a range of estimates taking into account diverse socioeconomic and climatic scenarios. On the other hand, it applies to SLR uncertainty. The main mechanism at work (even though not the only one) are changes in relative prices. These features are ill suited to capture either the propagation effects of disasters or their occurrence pattern. That would require full account of the whole probability distribution and potentially use of the apparatus of extreme value theory.

In fact, our aim is not to perform a risk analysis. To do this, other methodologies would be more appropriated (see Pol and Hinkel (2018) for a discussion on SLR uncertainty). Some studies adopt for instance probabilistic sea-level projections (e.g. Diaz, 2016). Decision analyses for coastal risk management also provide an alternative investigation approach which among other is able to represent more realistically local/site-specific features. Sahin and Mohamed (2014) combine a system dynamics model with a geographical information system for a spatial and temporal assessment of SLR. Tamura et al. (2019) use empirical econometric estimations to provide global economic assessments of SLR for different RCP/SSP combinations.

Moreover, there could be other macro-economic, but non-neo-classical modelling approaches, that could emphasize different outcomes. As said, for instance, demand-driven Keynesian or post-Keynesian models can measure and compare the multipliers associated to public and private consumption and investment and remove the simplifying assumption of perfect market clearing. Introducing market distortions and output gap is surely an important addition to the analysis of the public sector. Finally, the explicit introduction of financial markets could also provide different results based on the assumptions made.

Still, we believe that applying CGE modelling can provide useful insights on the higher order effects of public expenditure on adaptation (in this case against SLR), by systemically linking and capturing endogenous feedbacks across the taxation system, debt and debt services, GDP, and trade.

On this note, this methodology could be applied to wider contexts than SLR to examine the effect of climate change adaptation measures when the public sector plays an important role in replacing or supporting private actions. An example in this vein is public support in disaster risk reduction (e.g. in the area of riverine floods) where both damages and public support are substantive. In other areas where private adaptation or insurance are working, (e.g. in the health sector) this approach can be less useful.

\footnotetext{
${ }^{7}$ We thank an anonymous reviewer for pointing this out.
} 
Furthermore, the insights from our analysis support the idea of including long-term growth effects on cost-benefit analyses of climate change, considering also the trade-off between the adaptation (or mitigation) costs and long-term impacts that could accumulate in time affecting fiscal positions and growth in the long run.

\section{Conclusions}

This paper analyses the economic implications of publicly planned adaptation to protect coastal zones against SLR. Input to the analysis are labour productivity, land, and capital losses as well as coastal protection costs from DIVA model runs based on the combination of two SSPs (2 and $5)$, three RCPs $(2.6,4.5$, and 8.5), two climate models (NorESM and MIROC-ESM) and accounting also for land-based ice melt uncertainty (low, medium, and high). The economy-wide assessment is conducted with ICES-XPS, a multi-sector and multi-region CGE model enhanced with a detailed description of the public sector. Planned adaptation against SLR takes the form of public investments and expenditures for maintenance addressing the building sector. This expenditure is funded by issuing government bonds.

In a scenario where there is no additional adaptation, all world regions suffer a GDP loss. The most damaged countries are in Asia. When coastal protection takes place, the highest GDP gains compared to the case of no protection are observed mostly in Asian countries where SLR impacts are markedly high and adaptation expenditures particularly effective. In the remaining regions GDP gains are also experienced. The beneficial effect of adaptation on GDP is the result of two mechanisms. The first one regards the avoided direct impacts (i.e. loss of labour productivity, land, and capital). The second one is the public deficit effect. When adaptation to SLR reduces GDP losses, it also triggers a tax interaction effect which produces higher tax revenues for most regions, and lower public expenditures for Asian countries. Therefore, with lower deficits governments borrow less from households' savings and pay a lower debt service both of which allows for an increased capital accumulation and growth in the long run. This result is particularly interesting as the reduction of public deficits is one of the elements that contribute to increase savings, investments and eventually growth after adaptation has taken place.

Eventually, our study supports the intuition that large investments in adaptation not only can sustain, as amply acknowledged, GDP growth and development (being the avoided damages higher than adaptation costs), but also that this pro-growth push can be strong enough to trigger public debt reductions even when adaptation is financed in deficit spending. In general, this confirms the potential high returns of investment in adaption. This can be an important policy message either for countries where increasing tax pressures are particularly problematic or for those highly indebted countries where borrowing at competitive rates can be difficult. The former could think to use debt to finance their adaptation plans. The latter might find it easier to get funds on the market if they are earmarked toward adaptation investments that can be perceived as an element reducing the risk of no payback. This raises the issue of the different results that one could obtain through, for instance, earmarked taxation for adaptation that can potentially trigger different dynamics on debt accumulation and thus on the consumption-investment balance and growth. This will be a topic for future analysis. 


\section{References}

Aaheim A., Amundsen, H., Dokken, T., and T. Wei, (2012), Impacts and adaptation to climate change in European economies, Original Research Article, Global Environmental Change 22 (2012) 959-968

Bachner, G. \& Bednar-Friedl, B. Environ Model Assess (2018). https://doi.org/10.1007/s10666018-9617-3

Balk, D. L., Deichmann, U., Yetman, G., Pozzi, F., Hay, S. I., \& Nelson, A. (2006). Determining global population distribution: Methods, applications and data. In Global Mapping of Infectious Diseases: Methods, Examples and Emerging Applications (Vol.62:119-156). Elsevier.

Bentsen, M., I. Bethke, J. B. Debernard, T. Iversen, A. Kirkevåg, $\varnothing$. Seland, H. Drange, C. Roelandt, I. A. Seierstad, C. Hoose, and J. E. Kristjansson (2013). The Norwegian Earth System Model, NorESM1-M. Part 1: Description and basic evaluation of the physical climate, Geosci. Model Dev., 6:687-720, doi:10.5194/gmd-6-687-2013

Bosello, F., Carraro, C. and M. Galeotti (2001), "The double dividend issue: modelling strategies and empyrical findings", Environment and Development Economics, 6:9-45

Bosello F., Roson R., Tol R.S.J. (2007). Economy wide estimates of the implication of climate change: sea- level rise. Environmental Resource Economics, 37:549-571.

Bigano A, Bosello F, Roson R, Tol R (2008) Economy-wide impacts of climate change: a joint analysis for sea level rise and tourism. Mitig Adapt Strateg Glob Chang 13:765-791

Bosello F., Nicholls R.J., Richards J., Roson R. and Tol R., (2012a), "Economic Impacts of Climate Change in Europe: Sea-Level Rise", Climatic Change, 112:63-81.

Bosello F., Eboli, F., Pierfederici, R. (2012b). Assessing the Economic Impacts of Climate Change. An Updated CGE Point of View, Working Papers 2012.02, Fondazione Eni Enrico Mattei.

Bosello, F. and R. Parrado (2014). Climate change impacts and market driven adaptation: The costs of inaction including market rigidities. Working Papers 2014.64, Fondazione Eni Enrico Mattei.

Buchner B., Trabacchi C., Mazza F., Abramskiehn A. and Wang D. (2015). Global Landscape of Climate Finance 2015: A CPI Report. Climate Policy Initiative. Venice, Italy. Available at: http://climatepolicyinitiative.org/publication/global-landscape-of-climate-finance-2015/

CEPS and ZEW (2010). The fiscal implication of climate change adaptation. Final report of the ADAM project. Centre for European Policy Studies (CEPS) and Centre for European Economic Research (ZEW).

CIESIN, IFPRI, The World Bank, CIAT, (2011). Global Rural-Urban Mapping Project, Version 1 (GRUMPv1): Population Count Grid. Palisades, NY: NASA Socioeconomic Data and Applications Center (SEDAC. https://doi.org/10.7927/H4VT1Q1H)

Ciscar, J.C., Goodess, C., Christensen, O., et al. (2009), Climate change impacts in Europe Final report of the PESETA research project, Luxembourg, Publications Office of the European Union. http://dx.doi.org/10.2791/32500 
Ciscar JC, Iglesias A, Feyen L, Szabó L, Van Regemorter D, Amelunge B, Nicholls R, Watkiss P, Christensen OB, Dankers R, Garrote L, Goodess CM, Hunt A, Moreno A, Richards J, Soria A (2011) Physical and economic consequences of climate change in Europe. Proc Natl Acad Sci 108:2678-2683

Ciscar, JC., Szabó, L., van Regemorter, D. et al., (2012), The integration of PESETA sectoral economic impacts into the GEM-E3 Europe model: methodology and results, Climatic Change (2012) 112:127. https://doi.org/10.1007/s10584-011-0343-y

Ciscar JC, Feyen L, Soria A, et al., (2014). Climate Impacts in Europe. The JRC PESETA II Project. JRC Scientific and Policy Reports, http://dx.doi.org/10.2791/7409.

Ciscar, J.C., D. Ibarreta, A. Soria, A. et al., (2018), Climate impacts in Europe: Final report of the JRC PESETA III project, EUR 29427 EN, Publications Office of the European Union, Luxembourg, 2018, ISBN 978-92-79-97218-8, doi:10.2760/93257.

Church, J.A., P.U. Clark, A. Cazenave, J.M. Gregory, S. Jevrejeva, A. Levermann, M.A. Merrifield, G.A. Milne, R.S. Nerem, P.D. Nunn, A.J. Payne, W.T. Pfeffer, D. Stammer and A.S. Unnikrishnan, (2013), Sea Level Change. In: Climate Change 2013: The Physical Science Basis. Contribution of Working Group I to the Fifth Assessment Report of the Intergovernmental Panel on Climate Change [Stocker, T.F., D. Qin, G.-K. Plattner, M. Tignor, S.K. Allen, J. Boschung, A. Nauels, Y. Xia, V. Bex and P.M. Midgley (eds.)]. Cambridge University Press, Cambridge, United Kingdom and New York, NY, USA.

Darwin R.F., and R.S.J. Tol (2001). Estimates of the Economic Effects of Sea Level Rise. Environmental and Resource Economics,19:113-129.

Deke O, Hooss KG, Kasten C, Klepper G, Springer K (2001) Economic impact of climate change: simulations with a regionalized climate-economy model. Kiel Institute of World Economics, Kiel, 1065

Dellink, R., Lanzi, E., Chateau, J., Bosello, F., Parrado, R., De Bruin, K., (2014), Consequences of Climate Change Damages for Economic Growth. A Dynamic Quantitative Assessment, OECD Economics Department Working Papers, No.1135, OECD Publishing.

Delpiazzo E., Parrado R., Standardi G. (2017). Extending the public sector in ICES with an explicit government institution. Nota di Lavoro 11.2017, Milan, Italy: Fondazione Eni Enrico Mattei.

Diaz, D.B. (2016), Estimating global damages from sea level rise with the Coastal Impact and Adaptation Model (CIAM), Climatic Change (2016) 137:143. https://doi.org/10.1007/s10584016-1675-4

Eboli F., Parrado R. and Roson R. (2010). Climate-change feedback on economic growth: Explorations with a dynamic general equilibrium model. Environment and Development Economics, 15:515-533.

Ekins, P. \& Speck, S. (2013), The fiscal implications of climate change and policy responses, Mitig Adapt Strateg Glob Change (2014) 19:355. doi:10.1007/s11027-013-9533-4

Farid, M., Keen, M., Papaioannou, M.G., Parry, I.W.H., Pattillo, C., and Ter-Martirosyan, A. (2016). After Paris; Fiscal, Macroeconomic and Financial Implications of Global Climate Change, IMF Staff Discussion Notes 16/01, International Monetary Fund. 
Hallegatte, S., Green, C., Nicholls, R.J., Corfee-Morlot, J. (2013). Future flood losses in major coastal cities. Nature Climate Change. 3, 802-806

Heller P. (2003). Who Will Pay? Coping with Aging Societies, Climate Change, and Other LongTerm Fiscal Challenges. Washington D.C.: International Monetary Fund.

Hertel, T. W. (1997). Global trade analysis: modeling and applications. Cambridge: Cambridge University Press.

Hinkel J., Klein R.J.T. (2009). Integrating knowledge to assess coastal vulnerability to sea-level rise: the development of the DIVA model. Global Environmental Change, 19:384-395.

Hinkel J., Brown S., Exner L., Nicholls R.J., Vafeidis A.T., Kebede A.S. (2012). Sea-level rise impacts on Africa and the effects of mitigation and adaptation: an application of DIVA. Regional Environmental Change, 12:207-224.

Hinkel J., van Vuuren D.P., Nicholls R.J., Klein R.J.T. (2013). The effects of adaptation and mitigation on coastal flood impacts during the 21st century. An application of the DIVA and IMAGE models. Climatic Change, 117:783-794.

Hinkel J., Lincke D., Vafeidis A.T., Perrette M., Nicholls R.J., Tol R.S.J., Marzeion B., Fettweis X., lonescu C., Levermann A. (2014). Coastal flood damage and adaptation costs under 21st century sea-level rise. PNAS, 111 (9):3292-3297.

Hinkel, J., C. C. Jaeger, R. J. Nicholls, J. Lowe, O. Renn, and S. Peijun (2015). Sea-level rise scenarios and coastal risk management. In: Nature Climate Change 5. DOI:10. 1038/nclimate2505.

Hochrainer-Stigler, S., Mechler, R., Pflug, G., and Williges, K., (2014), Funding public adaptation to climate-related disasters. Estimates for a global fund, Global Environmental Change, Volume 25:87-96,

Hoegh-Guldberg, D. Jacob, M. Taylor, M. Bindi, S. Brown, I. Camilloni, A. Diedhiou, R. Djalante, K. Ebi, F. Engelbrecht, J. Guiot, Y. Hijioka, S. Mehrotra, A. Payne, S. I. Seneviratne, A. Thomas, R. Warren, G. Zhou, (2018), Impacts of $1.5^{\circ} \mathrm{C}$ Global Warming on Natural and Human Systems. In: Global warming of $1.5^{\circ} \mathrm{C}$. An IPCC Special Report on the impacts of global warming of $1.5^{\circ} \mathrm{C}$ above pre-industrial levels and related global greenhouse gas emission pathways, in the context of strengthening the global response to the threat of climate change, sustainable development, and efforts to eradicate poverty [V. Masson-Delmotte, P. Zhai, H. O. Pörtner, D. Roberts, J. Skea, P.R. Shukla, A. Pirani, W. Moufouma-Okia, C. Péan, R. Pidcock, S. Connors, J. B. R. Matthews, Y. Chen, X. Zhou, M. I. Gomis, E. Lonnoy, T. Maycock, M. Tignor, T. Waterfield (eds.)]. In Press.

International Institute for Applied System Analysis (2016). Shared Socioeconomic Pathways Database, https://secure.iiasa.ac.at/web-apps/ene/SspDb

Jarvis, A., Reuter, H. I., Nelson, A., \& Guevara, E. (2008). Hole-filled SRTM for the globe Version 4. Retrieved from the CGIAR-CSI SRTM 90m Database http://srtm.csi.cgiar.org

Jones, B., Keen, M. \& Strand, J. (2013), Fiscal implications of climate change, Int Tax Public Finance, 20:29. doi:10.1007/s10797-012-9214-3

Joshi, S.R., Vielle, M., Babonneau, F. et al. (2016), Physical and Economic Consequences of Sea-Level Rise: A Coupled GIS and CGE Analysis Under Uncertainties, Environ Resource Econ (2016) 65:813. https://doi.org/10.1007/s10640-015-9927-8 
McGranahan DA, Balk D, Anderson B. 2007. The rising tide: assessing the risks of climate change and human settlements in low elevation coastal zones. Environ. Urban. 19:17-39

Muis, S., Verlaan, M., Nicholls, R., Brown, S., Hinkel, J., Lincke, D., Vafeidis, A. T., Scussolini, P., Winsemius, H.C. and Ward, P.J., (2017), A comparison of two global datasets of extreme sea levels and resulting flood exposure. Earth's Future, 5:379-392. doi:10.1002/2016EF000430

Neumann B, Vafeidis AT, Zimmermann J, Nicholls RJ (2015) Future Coastal Population Growth and Exposure to Sea-Level Rise and Coastal Flooding - A Global Assessment. PLoS ONE10(3):e0118571. https://doi.org/10.1371/journal.pone.0118571

Nicholls, R., Hoozemans, F., and Marchand, M. (1999), Increasing flood risk and wetland losses due to global sea-level rise: regional and global analyses, Global Environmental Change, Volume 9, Supplement 1.

Nicholls, R.J., P.P. Wong, V.R. Burkett, J.O. Codignotto, et al., (2007), Coastal systems and lowlying areas. Climate Change 2007: Impacts, Adaptation and Vulnerability. Contribution of Working Group II to the Fourth Assessment Report of the Intergovernmental Panel on Climate Change, M.L. Parry, O.F. Canziani, J.P. Palutikof, P.J. van der Linden and C.E. Hanson, Eds., Cambridge University Press, Cambridge, UK, 315-356.

Nicholls R., Brown S., Hanson S., and Hinkel J. (2010). Economics of Coastal Zones Adaptation to Climate Change. Discussion Paper no.10. The World Bank: Washington.

OECD (2015), The Economic Consequences of Climate Change, OECD Publishing, Paris.

O’Neill B.C., Kriegler E., Riahl K., Ebi K.L., Hallegatte S., Carter T.R., Mathur R., van Vuuren D., (2014), A new scenario framework for climate change research: the concept of shared socioeconomic pathways. Climatic Change, 122:387-400.

Osberghaus D., Reif C. (2010). Total Costs and Budgetary Effects of Adaptation to Climate Change: An Assessment for the European Union. ZEW Discussion Paper no. 10-046. Mannheim: Center for European Economic Research.

Park, A. and Pezzey, J.C.V., (1998), "Variations on the Wrong Themes? A Structured Review of the Double Dividend Debate", in T.Sterner (ed.), Environmental Implications of Market based Policy Instruments, Cheltenham: Edwar Elgar.

Peltier, W. R. (2004). Global glacial isostasy and the surface of the ICE-age earth: The ICE-5G (VM2) model and GRACE. Annual Review of Earth and Planetary Sciences, 32(1), 111-149.

Pycroft J, Abrell J, Ciscar J-C (2015) The global impacts of extreme sea-level rise: a comprehensive economic assessment. Environ Resour Econ 1-29.

Roson R, van der Mensbrugghe D (2012) Climate change and economic growth: impacts and interactions. Int J Sustain Econ 4(3):270-285

Sahin, O. and Mohamed, S., (2014), Coastal vulnerability to sea-level rise: a spatial-temporal assessment framework, Nat Hazards, 70: 395. https://doi.org/10.1007/s11069-013-0818-4

Schoeb R., (2005), "The Double Dividend Hypothesis of Environmental Taxes: A Survey", in: Henk Folmer and Tom Tietenberg (eds.): The International Yearbook of Environmental and Resource Economics 2005/2006, Edgar Elgar: Cheltenham, 223-279. 
Sue Wing I, Fisher-Vanden K (2013) Confronting the Challenge of Integrated Assessment of Climate Adaptation: A Conceptual Framework. Climatic Change, 117:497-514

Tamura, M., Kumano, N., Yotsukuri, M., Yokoki, H (2019) Global assessment of the effectiveness of adaptation in coastal areas based on RCP/SSP scenarios. Clima Chang 152 $(3-4): 363-377$

Tol R.S.J,, Nicholls, R., Brown, S., Hinkel, J., Vafeidis, A., Spencer, T., and Schuerch, M. (2016), Comment on 'The Global Impacts of Extreme Sea-Level Rise: A Comprehensive Economic Assessment', Environ Resource Econ (2016) 64:341. doi:10.1007/s10640-015-9993-y

UNEP 2016. The Adaptation Finance Gap Report 2016. United Nations Environment Programme (UNEP), Nairobi

USGS (2015). Global 30 Arc-Second Elevation (GTOPO30) dataset. Retrieved from https://lta.cr.usgs.gov/GTOPO30

Vafeidis, A. T., R. J. Nicholls, L. McFadden, R. S. J. Tol, J. Hinkel, T. Spencer, P. S. Grashoff, G. Boot, and R. J. T. Klein (2008). A new global coastal database for impact and vulnerability analysis to sea-level rise, Journal of Coastal Research 24.4, pp917-924. doi:10.2112/06-0725.1.

van der Pol, T.D., Hinkel, J (2019) Uncertainty representations of mean sea-level change: a telephone game?. Clim Chang 152 (3-4):393-411

van Vuuren, D.P., Edmonds, J., Kainuma, M. et al. (2011), The representative concentration pathways: an overview, Climatic Change (2011) 109:5. doi:10.1007/s10584-011-0148-z

Watanabe, S., T. Hajima, K. Sudo, T. Nagashima, et al. (2011), MIROC-ESM 2010: model description and basic results of CMIP5-20c3m experiments, Geosci. Model Dev., 4, 845-872, http://www.geosci-model-dev.net/4/845/2011/

Wong, PP., Losada, IJ., Gattuso, J., et al (2014). Coastal systems and low-lying areas. In: Field $\mathrm{C}$ et al (eds) Climate change 2014: impacts, adaptation, and vulnerability. Part A: global and sectoral aspects. Cambridge University Press, Cambridge, UK and New York, USA, pp361-409

World Bank (2010). The Economics of Adaptation to Climate Change (EACC): Synthesis Report. The World Bank Group, Washington, DC.

World Bank (2017). World Development Indicators. The World Bank Group, Washington, DC. Accessed online on March 2017. 


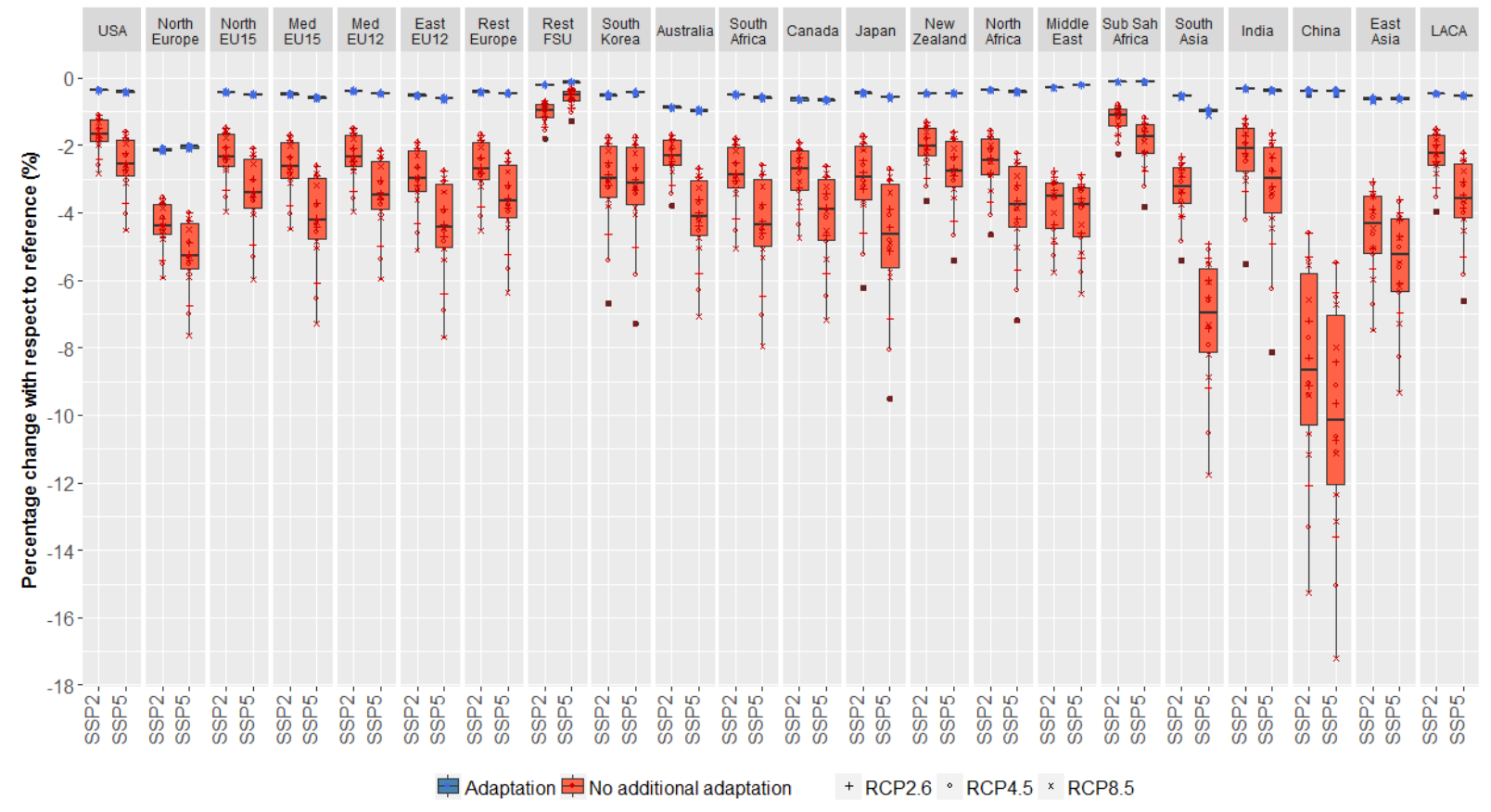

Fig. 1 Impacts on real GDP by region, SSP, and RCP in 2050 (with and without additional adaptation) 


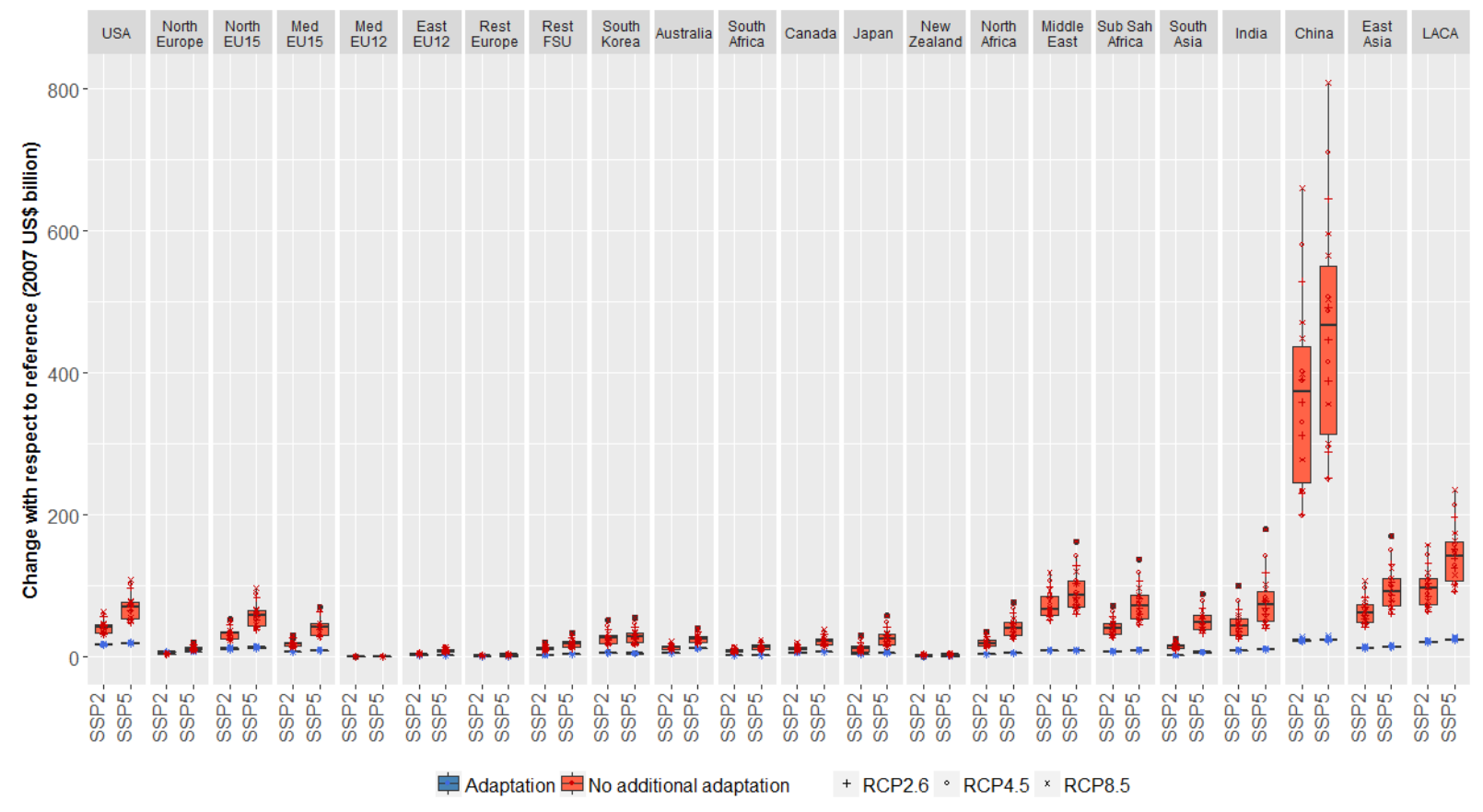

Fig. 2 Impacts on public deficit by region, SSPs and RCPs in 2050 (with and without additional adaptation) 


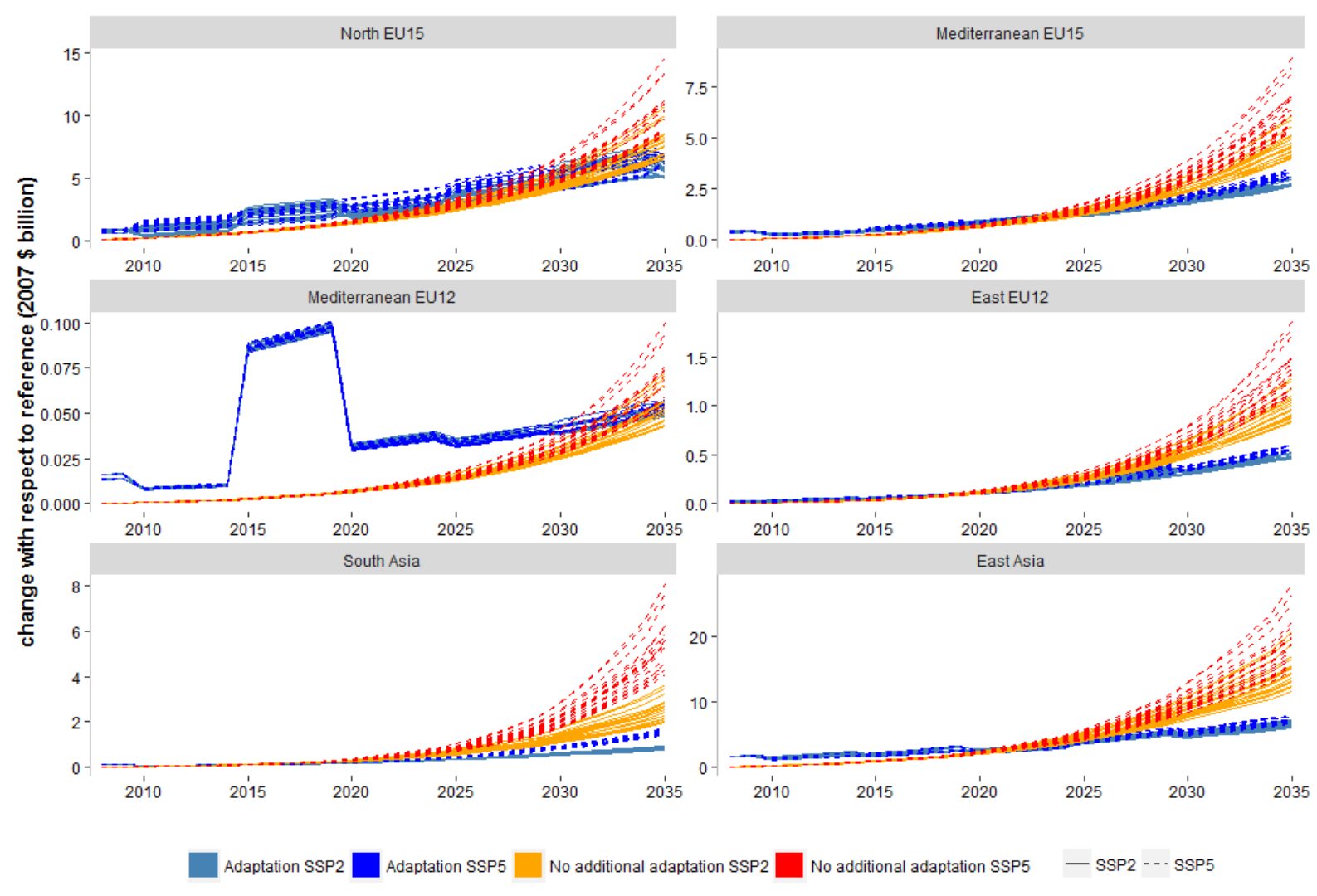

Fig. 3 Impacts on public deficit by SSP and RCP for selected regions (with and without additional adaptation) 